\title{
Soil organic carbon in the Sanjiang Plain of China: storage, distribution and controlling factors
}

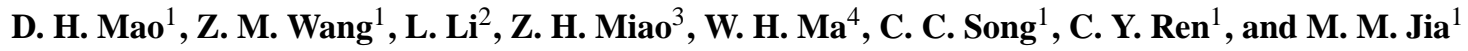 \\ ${ }^{1}$ Key Laboratory of Wetland Ecology and Environment, Northeast Institute of Geography and Agroecology, Chinese \\ Academy of Sciences, Changchun 130102, China \\ ${ }^{2}$ Department of Earth Sciences, Indiana University-Purdue University, Indianapolis 46202, USA \\ ${ }^{3}$ Jilin Province Water Resource and Hydropower Consultative Company of P. R. China, Changchun 130021, China \\ ${ }^{4}$ College of Life Science, Inner Mongolia University, Huhhot, Inner Mongolia Autonomous Region 010021, China
}

Correspondence to: Z. M. Wang (zongmingwang@iga.ac.cn)

Received: 8 August 2014 - Published in Biogeosciences Discuss.: 17 October 2014

Revised: 6 February 2015 - Accepted: 25 February 2015 - Published: 16 March 2015

\begin{abstract}
The accurate estimation of soil organic carbon (SOC) storage and determination of its pattern-controlling factors is critical to understanding the ecosystem carbon cycle and ensuring ecological security. The Sanjiang Plain, an important grain production base in China, is typical of ecosystems, yet its SOC storage and pattern has not been fully investigated because of insufficient soil investigation. In this study, 419 soil samples obtained in 2012 for each of the three soil depth ranges $0-30,30-60$, and $60-100 \mathrm{~cm}$ and a geostatistical method are used to estimate the total SOC storage and density (SOCD) of this region. The results give rise to $2.32 \mathrm{Pg} \mathrm{C}$ for the SOC storage and $21.20 \mathrm{~kg} \mathrm{~m}^{-2}$ for SOCD, which is higher than the mean value for the whole country. The SOCD shows notable changes in lateral and vertical distribution. In addition, vegetation, climate, and soil texture, as well as agricultural activities, are demonstrated to have remarkable impacts on the variation in SOCD of this region. Soil texture has stronger impacts on the distribution of SOCD than climate in the Sanjiang Plain. Specifically, clay content can explain the largest proportion of the SOC variations $(21.2 \%$ in the top $30 \mathrm{~cm})$ and is the most dominant environmental controlling factor. Additionally, the effects of both climate and soil texture on SOCD show a weakening with increasing soil layer depth. This study indicates that reducing the loss of SOC requires effective conservation and restoration efforts of wetlands and forestlands, as well as sensible fertilization. The results from this study provide the most up-to-date knowledge on the storage and pattern of SOC in the Sanjiang Plain and have important implications
\end{abstract}

for the determination of ecosystem carbon budgets and understanding ecosystem services.

\section{Introduction}

Soil is the largest terrestrial organic carbon pool, contains twice as much carbon as pools in the atmosphere or vegetation (Batjes, 1996), and plays an important role in the global carbon cycle. Accurate quantification of soil organic carbon (SOC) storage and further investigating its association with environmental factors is essential to in-depth analyses of the terrestrial carbon cycle and updating the carbon budget (Conant et al., 2011; Dorji et al., 2014; Piao et al., 2009).

In the past decades, numerous studies were undertaken to investigate the storage and distribution heterogeneity of SOC in different regions, which include the North American Arctic (Ping et al., 2008), the Amazon (Batjes and Dijkshoorn, 1999), British moorland (Garnett et al., 2001), Laos (Chaplot, et al., 2010), France (Martin et al., 2011), and China (Ni, 2013; Yu et al., 2007). Globally, $32 \%$ of SOC is stored in tropical soils, and mainly in forest soils (Eswaran et al., 1993). In China, the total SOC storage has been estimated using field samples, and the value was $89.61 \mathrm{Pg} \mathrm{C}$ in the $1980 \mathrm{~s}$ and $86.75 \mathrm{Pg} \mathrm{C}$ in the 2000s ( $\left.1 \mathrm{Pg} \mathrm{C}=10^{15} \mathrm{gC}\right)$, representing $\sim 5.0 \%$ of the world's storage (Xie et al., 2007). However, the larger of the two estimated SOC values indicates a need to improving SOC estimation on regional and local scales to accurately update the world and national SOC budget. 
The storage and distribution heterogeneity of SOC depend on climate conditions (Davidson and Janssens, 2006), land-use patterns (Poeplau and Don, 2013; Yu et al., 2012), and human activities and policies (Cao et al., 2011a, 2011b; Heikkinen et al., 2013; Wang et al., 2011). The distribution of SOC has been correlated with various climate factors, soil texture, and land cover types (Batjes and Dijkshoorn, 1999; Jobbágy and Jackson, 2000; Li and Zhao, 2001; Saiz et al., 2012; Wang et al., 2004; Yang et al., 2007). Globally, total SOC content has been shown to increase with precipitation but decrease with temperature, and the two climate factors control SOC in shallow soil layers (Jobbágy and Jackson, 2000). Jobbágy and Jackson (2000) also showed that total SOC increases with clay content, which drives SOC in deeper soil layers. Plant functional types can significantly impact the vertical distribution of SOC (Jobbágy and Jackson, 2000; Yang et al., 2010). Although the influence of climate, vegetation, and soil texture on SOC storage has been noticed (Chaplot et al., 2010; Liu et al., 2011; Yang et al., 2008), it has been difficult to assess this influence because of large uncertainties in characterizing the distribution of SOC. One reason for this difficulty is a lack of appropriate data. A large amount of data from recent field investigations is required to facilitate the assessment of SOC storage in typical regions.

The Sanjiang Plain is one of the main food and agricultural bases and has the largest natural wetland in China (Wang et al., 2011). A typical monsoon climate in midlatitudes, diverse land-cover types, dramatic land-use changes, and other human disturbances in recent decades (Song et al., 2014) make it an ideal region for investigating the pattern and environmental controls of the SOC storage in northeast Asia. Previous studies have mainly focused on the topsoil organic carbon and used a limited number of soil profiles measured in this area, which would not allow for a comprehensive investigation on and a comparison of the lateral and vertical distribution of SOC in various ecosystems (Wang et al., 2002). In addition, significant wetland reclamation, conversion from dry farmland to paddy field, and intensive chemical fertilizer applications have been observed in this region (Wang et al., 2011), which could have implications for the SOC cycle. These considerations create the need for studying the current SOC storage and distribution as well as their associations with various environmental factors so that regional soil carbon sources or sinks can be determined for this region.

In this study, the SOC storage in the Sanjiang Plain was estimated based on extensive $1 \mathrm{~m}$ depth soil profiles. The primary objective of the study was to further characterize the SOC of this region. The secondary objectives were to (1) estimate the SOC storage and map its lateral and vertical distribution, (2) compare SOC across different terrestrial land-cover types, and (3) examine the associations of environmental factors with the lateral and vertical variability of SOC storage.

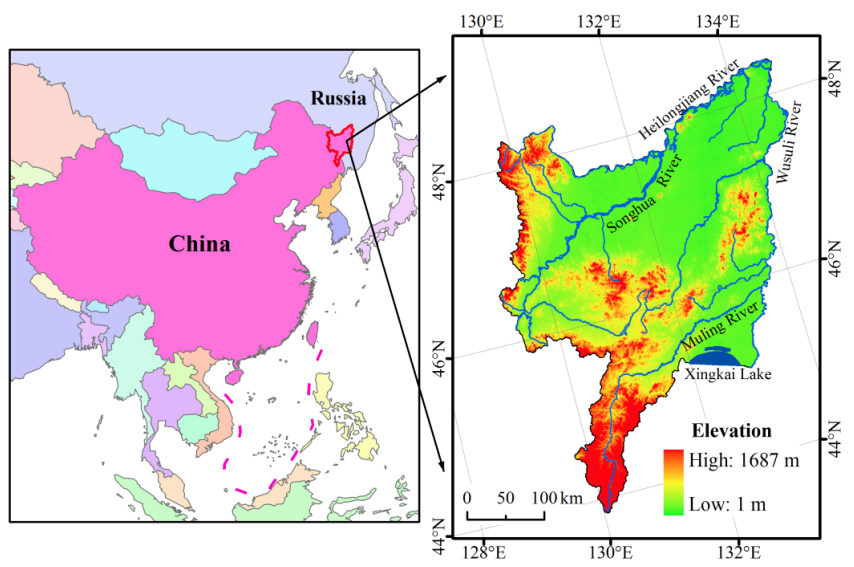

Figure 1. Position and terrain of the Sanjiang Plain.
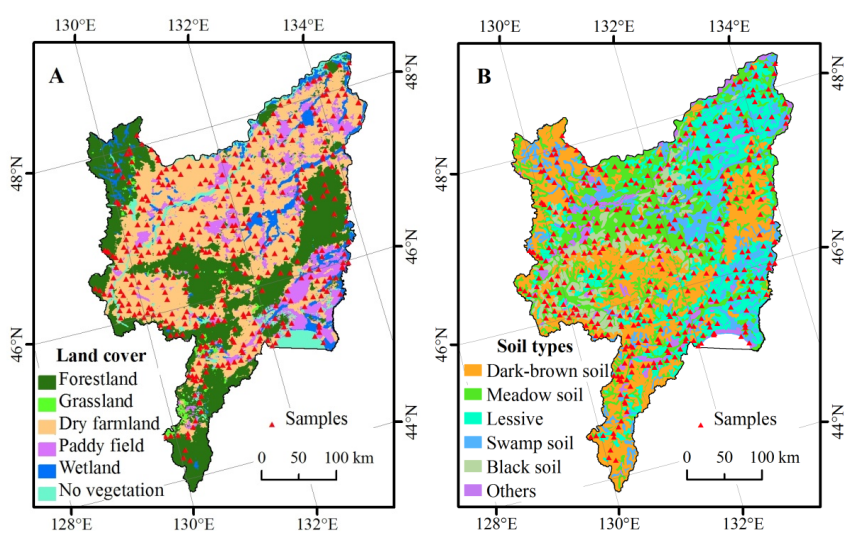

Figure 2. Spatial distribution of field samples, land cover (a) and soil types (b) in the Sanjiang Plain.

\section{Data and methods}

\subsection{Study area}

The Sanjiang Plain is located in the northeast corner of China and separated from Russia by the Heilongjiang and Wusuli rivers (Fig. 1). The region has 23 counties and extends from $129^{\circ} 11^{\prime}$ to $134^{\circ} 47^{\prime} \mathrm{E}$ in longitude and from $43^{\circ} 49^{\prime}$ to $48^{\circ} 25^{\prime} \mathrm{N}$ in latitude, with a total area of $108596 \mathrm{~km}^{2}$ (Wang et al., 2011). It is a low alluvial plain deposited by the Heilongjiang, Songhua, and Wusuli rivers, with elevation in the southwest being higher than in the northeast. Annual precipitation is between 500 and $650 \mathrm{~mm}$, and $80 \%$ of rainfall occurs in growing seasons (May to September). The mean air temperature ranges from 1.4 to $4.3^{\circ} \mathrm{C}$, and the frost-free period is 120-140 days. The climate of this area belongs to the temperate humid or subhumid continental monsoon climate (Wang et al., 2006), which is suitable for natural wetlands and for growing grains. 


\subsection{Land-cover and soil-type data sets}

The Landsat thematic mapper (TM) and Chinese Huan Jing (HJ) satellite images (Zhang et al., 2014) acquired in 2010 for the study region were classified using the eCognition software to extract land-cover data (Mao et al., 2014a). All the images (32 of them being TM and 6 being HJ) were atmospherically corrected using the $6 \mathrm{~S}$ radiative transfer model and were geometrically rectified. Furthermore, based on the digital elevation model (DEM) and field investigations, image segmentation was performed for these satellite images. Validation of the land-cover classification on the field data collected in 2010 (1326 points) resulted in a kappa coefficient of 0.894 and an overall accuracy of $89 \%$. The area for each land-cover type was calculated using the ArcMap software. Statistic results further revealed that the major landcover types in the Sanjiang Plain were cropland, forestland, and wetland (Fig. 2a), with an area of 59531.49, 36556.49 , and $6527.89 \mathrm{~km}^{2}$, respectively.

The soil-type data set covering the Sanjiang Plain was taken from the soil map of China, resulting from the second Chinese soil investigations on a scale of $1: 1000000$ (Wang et al., 2006). The five main soil types in the area were dark-brown soil, meadow soil, lessive, swamp soil, and black soil, and they occupied more than $95 \%$ of the whole area (Fig. 2b). In the Sanjiang Plain, dark-brown soil and meadow soil are the largest and second-largest soil types, with an area of 32103.54 and $31017.36 \mathrm{~km}^{2}$, respectively. Considering that the SOC content and density differ among soil types (Mao et al., 2014b; Yu et al., 2007), different soil types need to be accommodated in the deployment of field sampling sites.

\subsection{Soil sampling and determination}

Soil samples were collected in 2012 on the basis of visual navigation via a GPS unit linked to an ArcGIS-installed laptop. Each of these samples was collected using a standard container with a volume of $100 \mathrm{~cm}^{3}$ and a cloth pocket. For each soil site (three soil profiles at each site), the SOC content for each depth range (i.e., 0-30, 30-60, and 60-100 cm) was represented by the average of SOC values of three spatially random profiles at the sampling site. Land-cover types, sampling time and depth, and geographic locations were recorded while sampling. Because of the inaccessibility of some land-cover types and the areal difference of land-cover types, a total of 419 soil samples (59 for forestland, 13 for grassland, 59 for paddy field, 206 for dry farmland, and 82 for wetland) for each soil depth range were obtained, and their locations were overlaid on the land-cover and soil types as shown in Fig. 2.

All of the soil samples were air-dried and then oven-dried at $105^{\circ} \mathrm{C}$ to determine their bulk densities. Visible plant detritus and all rock fragments were removed from the soil samples in the cloth pockets before the soil samples were fur- ther processed by grinding and sieving with $2 \mathrm{~mm}$ meshes and analyzed for SOC concentration and soil texture. The SOC concentration was measured by wet combustion with $\mathrm{K}_{2} \mathrm{Cr}_{2} \mathrm{O}_{7}$ (Yang et al., 2007). A Mastersizer 2000 instrument was used to measure the soil texture of 80 sample profiles equally distributed in the study area, including clay content $(<0.002 \mathrm{~mm})$, silt content $(0.02-0.002 \mathrm{~mm})$, and sand content $(0.02-2 \mathrm{~mm})$.

\subsection{Climate data}

The mean annual temperature (MAT) and mean annual precipitation (MAP) were calculated from the meteorological data recorded during 1981-2012. All of these data were downloaded from the National Climatic Data Center of the NOAA (NCDC, http://www.ncdc.noaa.gov/) and the China Meteorological Data Sharing Service System (http://cdc. cma.gov.cn). To improve the accuracy of the spatial interpolation of climate factors, 35 meteorological stations (12 of them being in Russia and 23 in China) were used and spatially interpolated using the kriging method. The MAT and MAP for each sampling site were extracted based on its geographical position from the interpolated raster with a spatial resolution of $8 \mathrm{~km}$.

\subsection{Amounts of fertilizer}

The amounts of fertilizer for each of the 23 counties in the Sanjiang Plain was obtained from the statistical yearbook of Heilongjiang Province in 2012. The ratio $\left(\mathrm{kg} \mathrm{ha}^{-1}\right)$ of the amount of fertilizer to the area of croplands of each county was calculated. A relation of the fertilization amount to the SOC content was derived for the individual soil layers considered in this study.

\subsection{Estimation of SOC storage}

This study analyzed the spatial distribution of soil organic carbon density (SOCD) within different soil depth ranges ( 0 $30,0-60$, and $0-100 \mathrm{~cm})$. The SOCD and SOC storage at a depth of $h(\mathrm{~cm})$ were calculated as follows:

$\operatorname{SOCD}_{h}=\sum_{i=1}^{n} \frac{\left(1-\delta_{i} \%\right) \times \rho_{i} \times C_{i} \times T_{i}}{100}$

$\mathrm{SOC}_{h}=\mathrm{SOCD}_{h} \times A R E A$,

where $n$ is the number of the soil layer, $\delta_{i}$ is the concentration of gravel larger than $2 \mathrm{~mm}$ in the $i$ th soil layer (volume percentage), $\rho_{i}$ and $C_{i}$ are the bulk density and the SOC content $\left(\mathrm{g} \mathrm{kg}^{-1}\right)$ in the $i$ th soil layer, respectively, and $T_{i}$ is the thickness of the $i$ th soil layer.

The kriging interpolation and the semivariable function were used to determine the spatial distribution of SOC. Kriging is a geostatistical method that is commonly used to interpolate an SOCD data set from discrete points to a spatially continuous surface (Kumar et al., 2012; Khalil et al., 

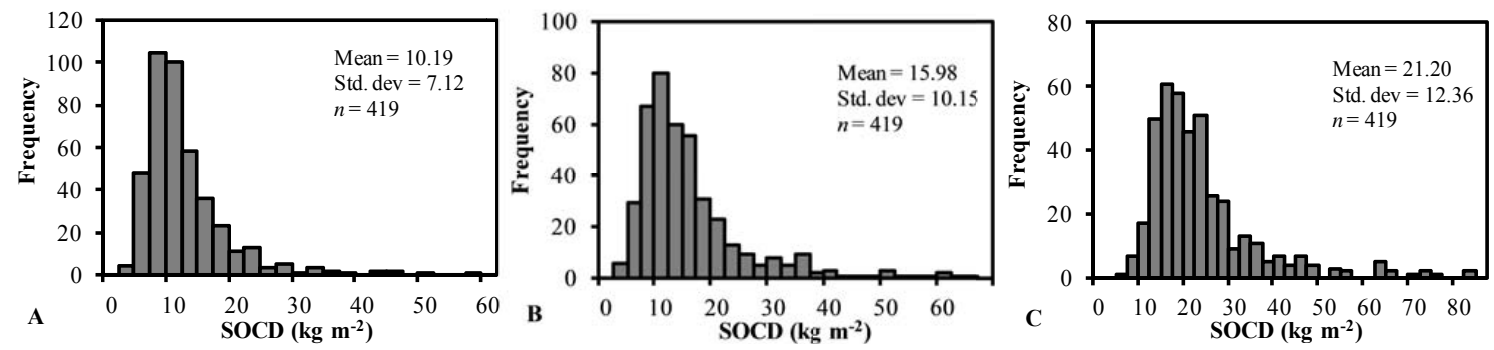

Figure 3. Frequency distributions of SOCD at different soil depth ranges ((a): 0-30 cm; (b): 0-60 cm; (c): 0-100 cm).
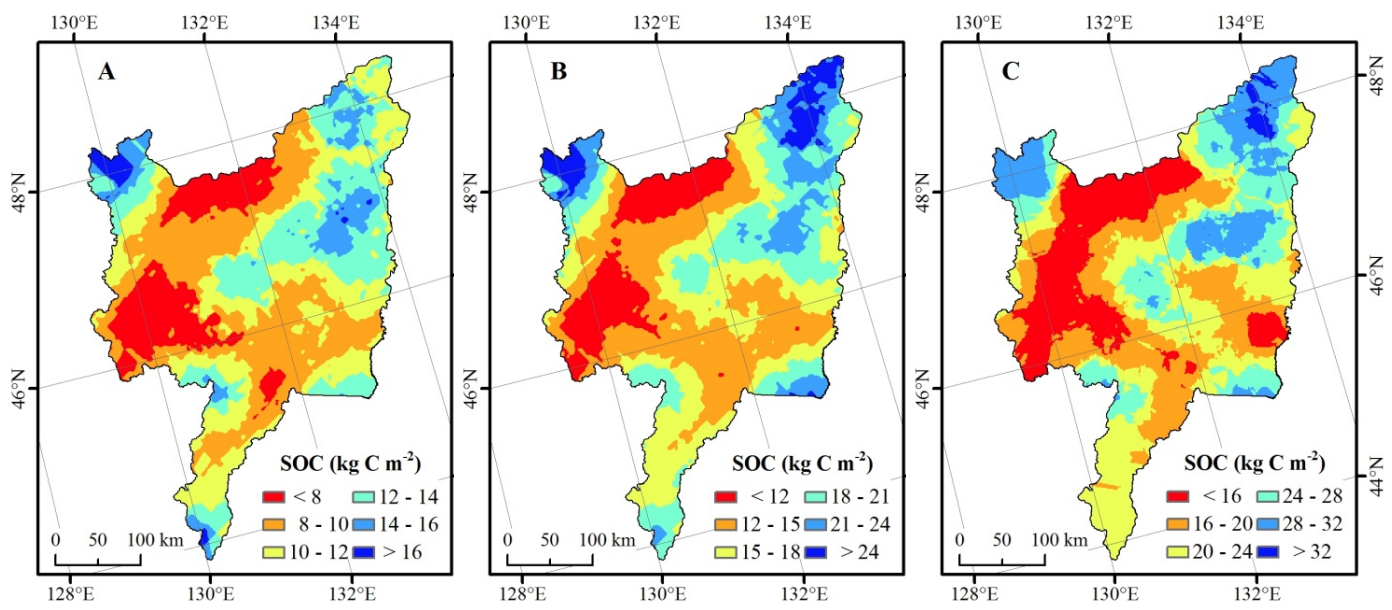

Figure 4. Spatial pattern of SOC storage at different soil depths ((a): 0-30 cm; (b): 0-60 cm; (c): 0-100 cm).

2013), and the semivariable function can be used to quantify the spatial autocorrelation and provides an input parameter for a spatial interpolation (Liu et al., 2011). All of the calculations for mapping SOC within individual soil depth ranges were performed using the ArcGIS software (Version 9.3).

\subsection{Statistical analysis}

The general linear model (GLM) was used to determine the relationship between SOCD and each of the different environmental factors (MAT, MAP, clay content, silt content, and sand content) and to assess how each factor influences the variation in SOC within a soil depth range (Yang et al., 2007). All GLM analyses were performed with the software package R (R Development Core Team 2005).

The coefficient of determination $\left(R^{2}\right)$ and the correlation coefficient $(p)$ obtained from regressive and correlative analyses performed with the SPSS software were employed to describe the effects of individual controlling factors on SOC, such as climate factors and soil parameters. In addition, the estimated SOCD for the Sanjiang Plain was compared to the SOCD values estimated for different regions of the world to investigate the effects of climate factors and vegetation.

To address the effects of agricultural activities on the distribution of SOC, we examined the correlation of the amount of applied fertilizers to the SOC content on the county scale.

\section{Results}

\subsection{Storage and spatial distribution of SOC}

The SOCD of the 419 sampling profiles varied remarkably within each soil depth range (Fig. 3). The mean SOCD values of all sample profiles for the three depth ranges $(0-30,0-60$, and $0-100 \mathrm{~cm}$ ) were $10.19,15.98$, and $21.20 \mathrm{~kg} \mathrm{~m}^{-2}$, and the standard deviations of the corresponding SOCD were 7.12, 10.15 , and $12.36 \mathrm{~kg} \mathrm{~m}^{-2}$, respectively. Excluding the regions of water bodies, the total SOC storage of the Sanjiang Plain was estimated to be $1.16 \mathrm{Pg} \mathrm{C}$ for the depth range $0-30 \mathrm{~cm}$, $1.80 \mathrm{Pg} \mathrm{C}$ for $0-60 \mathrm{~cm}$, and $2.32 \mathrm{Pg} \mathrm{C}$ for $0-100 \mathrm{~cm}$.

The spatial variation in SOC storage within the soil depth range is apparent (Fig. 4). For the soil depth range of 0 $60 \mathrm{~cm}$, high SOCD values are mainly present in the northeast, the northwest corner, and small areas of the north, whereas low SOCD values are present in the north central area and the southwest. For the soil depth range of $0-100 \mathrm{~cm}$, the SOC storage values higher than $24 \mathrm{~kg} \mathrm{C} \mathrm{m}^{-2}$ mainly appear in the northeast and northwestern corner of the Sanjiang Plain. 
Table 1. SOCD and SOC storage for different land-cover types in the Sanjiang Plain.

\begin{tabular}{lrrrrrrr}
\hline Land-cover & \multicolumn{2}{c}{ Area } & \multicolumn{3}{c}{ SOCD $\left(\mathrm{kg} \mathrm{m}^{-2}\right)$} & \multicolumn{3}{c}{ SOC storage $(\mathrm{Tg} \mathrm{C})$} \\
types & $\left(\mathrm{km}^{2}\right)$ & $0-30 \mathrm{~cm}$ & $0-60 \mathrm{~cm}$ & $0-100 \mathrm{~cm}$ & $0-30 \mathrm{~cm}$ & $0-60 \mathrm{~cm}$ & $0-100 \mathrm{~cm}$ \\
\hline Dry farmland & 41462.87 & 9.72 & 14.56 & 19.68 & 412.10 & 637.71 & 821.84 \\
Paddy field & 18068.62 & 9.88 & 15.53 & 19.79 & 191.00 & 302.24 & 388.14 \\
Grassland & 124.30 & 10.65 & 11.33 & 17.38 & 1.47 & 2.31 & 71.58 \\
Forestland & 36556.49 & 11.41 & 16.84 & 23.40 & 420.20 & 639.10 & 827.52 \\
Wetland & 6527.89 & 14.78 & 23.50 & 29.59 & 76.71 & 123.85 & 160.85 \\
\hline
\end{tabular}

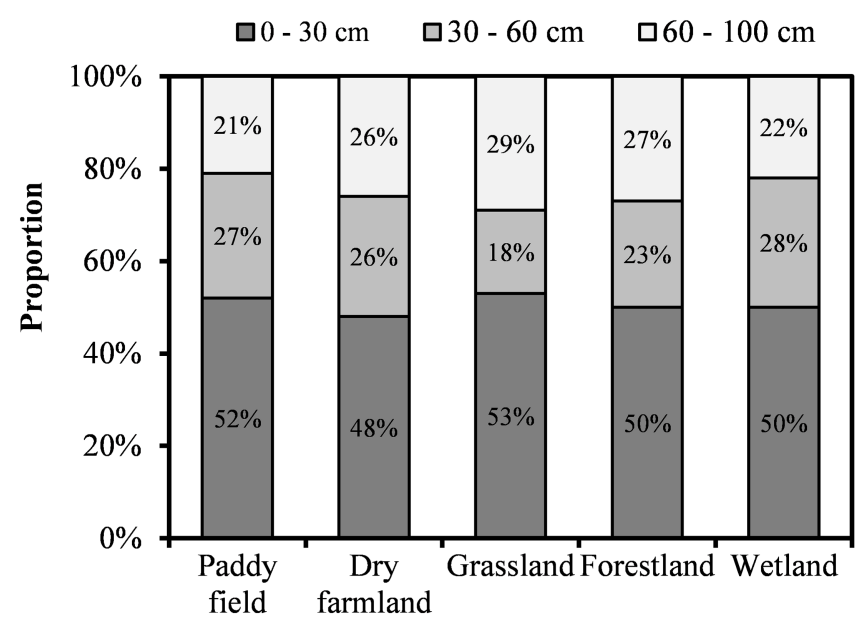

Land-cover types

Figure 5. Vertical distribution of SOC storage in different soil depth ranges for various land-cover types.

\subsection{Mean SOCD and SOC storage for different land-cover types}

Table 1 provides a detailed description of SOCD and SOC storage for different land-cover types of the Sanjiang Plain. The SOCD for the soil depth range $0-30 \mathrm{~cm}$ increases from dry farmland to paddy field, grassland, forestland, and wetland, in that order, whereas for the soil ranges of 0-60 and $0-100 \mathrm{~cm}$, it increase from grassland to dry farmland, paddy field, forestland, and wetland, in that order. Wetlands have the largest SOCD at all three soil depths $(0$ $30,0-60,0-100 \mathrm{~cm})$. Forestlands covering the second-largest area of the Sanjiang Plain have the second-largest SOCD (23.40 $\mathrm{kg} \mathrm{m}^{-2}$ ) among the land-cover types and stock the second-largest SOC $\left(827.52,1 \mathrm{Tg} \mathrm{C}=10^{12} \mathrm{~g} \mathrm{C}\right)$ in the soil depth range of $0-100 \mathrm{~cm}$; forestlands and dry farmlands together account for $72.7 \%$ of SOC storage in the same depth range soil of the Sanjiang Plain.

\subsection{Vertical distribution characteristics of SOC storage for different land-cover types}

An apparent vertical differentiation in SOC storage can be observed in the Sanjiang Plain (Fig. 5). For the soil depth range of $0-100 \mathrm{~cm}$, approximately $49 \%$ of total SOC storage is concentrated within the top $30 \mathrm{~cm}$. The SOC storage within each soil depth range $(0-30,30-60$, and $60-100 \mathrm{~cm})$ varies significantly across different land-cover types. The percentage of SOC within the depth range $0-30 \mathrm{~cm}$ of the overall SOC within the range $0-100 \mathrm{~cm}$ is $48,50,50,52$, and $53 \%$ for dry farmlands, forestlands, wetlands, paddy fields, and grasslands, respectively, implying that the relative distribution of the SOC of the topsoil is the deepest in dry farmlands, intermediate in the forestlands and wetlands, and the shallowest in paddy fields and grasslands. These percentages also indicate that SOC storage decreases with soil depth when the paddy fields and wetlands are considered. In contrast, SOC storage increases from the depth range of 30-60 to $60-100 \mathrm{~cm}$ for grasslands and forestlands.

\subsection{Effects of environmental factors on SOCD}

SOC storage within different soil depth ranges is significantly affected by climate and soil texture. As shown in Fig. 6, SOCD in the Sanjiang Plain is not only significantly correlated with MAT (Fig. 6a1-a3) and MAP (Fig. 6b1b3) for the different soil depth ranges but strongly associated with soil texture as well (Fig. 6c1-e3 and Table 3). The SOCD in the depth ranges of $0-30,0-60$, and $0-100 \mathrm{~cm}$ of soil decreases with increasing MAT up to $\sim 4.6^{\circ} \mathrm{C}$ and then increases with MAT (Fig. 6a1-a3). Similarly, the SOCD for the different depth ranges decreases and then increases with soil clay content $(P<0.01$, Fig. $6 \mathrm{c} 1-\mathrm{c} 3)$. In addition, SOCD increases with MAP (Fig. 6b1-b3) and soil silt content (Fig. 6d1-d3). The SOCD shows a significantly negative correlation with sand content within the depth ranges of 0 60 and $0-100 \mathrm{~cm}$ but an insignificant correlation for the depth range of $0-30 \mathrm{~cm}$ (Fig. 6e1-e3).

Table 2 presents the results from the GLM, which reveal that environmental factors explain 57.78, 52.03, and $37.67 \%$ of the overall variation in SOCD for the depth ranges of 0 $30,0-60$, and $0-100 \mathrm{~cm}$, respectively. Both the associations of climate and soil texture with SOCD are weak with increas- 

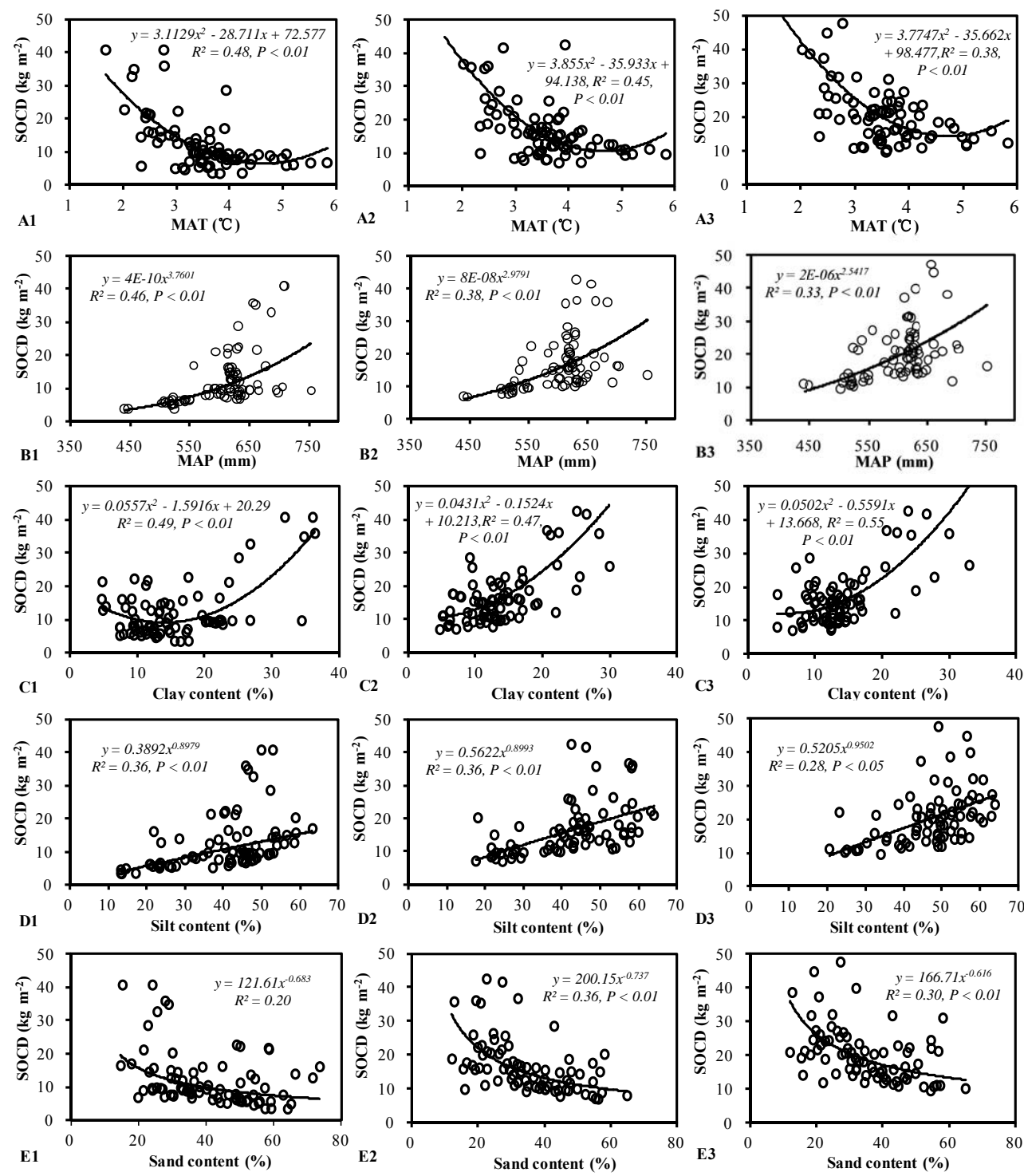

Figure 6. Correlations of SOCD with various environmental factors for different soil depths in the Sanjiang Plain ((a1-e1): 0-30 cm; (a2-e2): 0-60 cm; (a3-e3): 0-100 cm).

ing soil depth. Clay content explains the largest proportion of the SOCD variation $(21.20 \%$ for the range of $0-30 \mathrm{~cm}$, $18.30 \%$ for $0-60 \mathrm{~cm}$, and $15.40 \%$ for $0-100 \mathrm{~cm}$ ) and thus is the most dominant environmental variable. Silt content also plays an important role in shaping the pattern of SOC storage, explaining the second-largest proportion of SOCD variation. Therefore, soil texture has more impact on the distribution of SOCD than climate factors do in the Sanjiang Plain. When comparing temperature with precipitation, the former exhibits more significant effects on the SOCD within the depth range of $0-100 \mathrm{~cm}$ than the latter, as shown by a regressive coefficient (Fig. 6a3, b3) for temperature and greater variance of SOCD explained by temperature (Table 2).

The associations of climate and soil texture with vertical SOCD vary significantly (Table 3). For the different soil depths $(0-30,30-60,60-100 \mathrm{~cm})$, SOCD is negatively correlated with both MAT and sand content but positively correlated with MAP, clay content, and silt content. Clay content has the largest correlation coefficient with $\operatorname{SOCD}(P<0.01)$, meaning that it plays a more important role in driving the SOCD vertical distribution as compared to other environmental variables. The correlations between SOCD and sand content are found to be high for deeper soil depth ranges, whereas the correlations between SOCD and other examined controlling factors are low.

\subsection{Effects of fertilization amount on SOC storage}

We examined the amount of fertilizer and SOC content for croplands in the 23 counties and found that agricultural ac- 
Table 2. GLM results for correlating SOCD and environmental factors.

\begin{tabular}{llrrrrrr}
\hline Depth & Factors & MAT & MAP & Clay content & Silt content & Sand content & Others \\
\hline & DF & 1 & 1 & 1 & 1 & 1 & 80 \\
\hline $0-30 \mathrm{~cm}$ & MS & $0.87^{*}$ & $1.49^{*}$ & $4.70^{*}$ & $4.65^{*}$ & $2.40^{*}$ & 0.02 \\
& SS $(\%)$ & 4.23 & 5.21 & 21.20 & 17.80 & 9.34 & 42.22 \\
\hline \multirow{2}{*}{$0-60 \mathrm{~cm}$} & MS & $2.24^{*}$ & $1.45^{*}$ & $8.23^{*}$ & $6.54^{*}$ & $5.23^{*}$ & 0.05 \\
& $\mathrm{SS}(\%)$ & 5.21 & 3.22 & 18.30 & 15.20 & 10.10 & 47.97 \\
\hline $0-100 \mathrm{~cm}$ & MS & $1.11^{*}$ & 0.23 & $6.21^{*}$ & $5.07^{*}$ & $4.21^{*}$ & 0.07 \\
& $\mathrm{SS}(\%)$ & 1.65 & 0.68 & 15.40 & 12.40 & 7.54 & 62.33 \\
\hline
\end{tabular}

${ }^{*} P<0.01 ; \mathrm{DF}$ - degree of freedom; MS - mean squares; SS - sum of squares (the proportion of variances explained by a variable).

Table 3. Correlation coefficients between SOCD and environmental factors in different soil layers.

\begin{tabular}{cccccc}
\hline Soil depth $(\mathrm{cm})$ & MAT & MAP & Clay content & Silt content & Sand content \\
\hline $0-30$ & $-0.33^{\mathrm{b}}$ & $0.29^{\mathrm{b}}$ & $0.49^{\mathrm{b}}$ & $0.35^{\mathrm{b}}$ & -0.18 \\
$30-60$ & $-0.30^{\mathrm{b}}$ & $0.22^{\mathrm{a}}$ & $0.46^{\mathrm{b}}$ & $0.34^{\mathrm{b}}$ & $-0.37^{\mathrm{b}}$ \\
$60-100$ & -0.11 & 0.20 & $0.42^{\mathrm{b}}$ & $0.22^{\mathrm{a}}$ & $-0.38^{\mathrm{b}}$ \\
\hline
\end{tabular}

a $P<0.05$ ' $^{\mathrm{b}} P<0.01$

tivities, especially fertilization, have remarkable impacts on SOC content. Significantly negative correlations $(P<0.01)$ between the amount of fertilizer and SOC content are found for the $0-30$ and 30-60 cm depth ranges (Fig. 7). Moreover, the correlation between the amount of fertilizer and SOC content decreases with soil depth.

\section{Discussion}

\subsection{SOC estimates in the Sanjiang Plain}

Spatially explicit estimates of SOC on regional scales are vital for monitoring carbon sequestration, which impacts global climate change and food security (Lal, 2004a). In this study, extensive soil investigation that took land-cover types and soil types into consideration has been undertaken to quantify the SOC storage in the Sanjiang Plain. A geostatistical approach was further used to map the regional pattern of SOC in different soil depth ranges. The method that was used for estimating the regional carbon pool in the present study is different from that used by Yang et al. (2008), who estimated SOC storage by correlating SOC content with a remote-sensing vegetation index. Considering the rich ecosystem types of the Sanjiang Plain and coarseresolution remote-sensing imagery, this study used the kriging method to achieve a more accurate estimation of SOC than previous studies (Wang et al., 2002; Yu et al., 2007). The SOC estimates were based on a large-volume data set, including the most recently measured data.
Observed was the larger mean SOCD for the depth range of $0-100 \mathrm{~cm}\left(21.20 \mathrm{~kg} \mathrm{~m}^{-2}\right)$ in the Sanjiang Plain as compared to the reported mean SOCD of China $\left(7.8 \mathrm{~kg} \mathrm{~m}^{-2}\right.$; Yang et al., 2007) and the whole world $\left(10.8 \mathrm{~kg} \mathrm{~m}^{-2}\right.$; estimated by Post et al. (1982)), which is mostly due to a relatively low temperature as compared to the south and more precipitation than in the western part of the country, as well as extensive wetlands and forests in the Sanjiang Plain (Yu et al., 2007). In addition, the estimated SOCD value of 10.19 $\mathrm{kg} \mathrm{m}^{-2}$ for the depth range of $0-30 \mathrm{~cm}$ in the study area is higher than the $7.70 \mathrm{~kg} \mathrm{~m}^{-2}$ observed in the Loess Plateau of China (Liu et al., 2011) and the value of $5.91 \mathrm{~kg} \mathrm{~m}^{-2}$ for France (Martin et al., 2011). This is largely attributed to the humid climate and high natural vegetation (i.e., forest and wetland) cover. In this study, we have observed that forestlands have a higher SOCD than grasslands, which is different from the SOC results for China reported by Wang et al. (2004) and for France reported by Martin et al. (2011). We attribute these differences to the climate zones on which these studies have focused.

This study resulted in a total estimated SOC storage of $2.32 \mathrm{Pg} \mathrm{C}$ within the soil depth range of $0-100 \mathrm{~cm}$ in the Sanjiang Plain. Similar estimations yielded 26.43 Pg C for Northeast China (Wang et al., 2003) and 69.10 Pg C for all of China (Wu et al., 2003). Converting these two SOC storage values to $S O C D$ based on related publications would give rise to SOCD values for the Sanjiang Plain which are smaller than the SOCD result observed in this study. It is worth discussing which SOCD estimate is more accurate. 

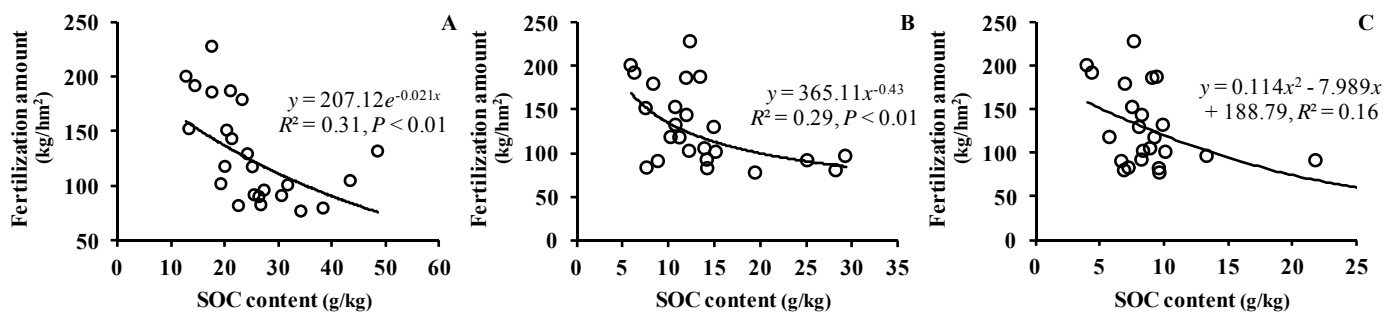

Figure 7. Correlations of cropland fertilization amount with SOC content in the Sanjiang Plain for different soil layers ((a): 0-30 cm; (b): 30-60 cm; (c): 60-100 cm).

Our results reveal that farmland has an SOCD value smaller than those for forestland and wetland. Figure 6 shows a negative correlation of SOCD with temperature and a positive correlation with precipitation. Additionally, the Sanjiang Plain experienced significant losses of both forestland and wetland to farmland, obvious increases in temperature, and notable decreases in precipitation (Wang et al., 2011; Song et al., 2014). All these factors should contribute to the loss of SOC storage. Therefore, we are confident that the present SOCD estimation is closer to the actual SOC storage in the Sanjiang Plain and that the previously reported SOCD for Northeast China and the whole country underestimated SOC storage.

\subsection{Impacts of land-cover type on SOC}

It has been pointed out that SOC storage strongly depends on land-cover types (Chaplot et al., 2010; Martin et al., 2011). Fig. 2 supports the same observation. It is thus necessary to discuss the impacts of land-cover types on SOC storage.

Jobbágy and Jackson (2000) and Yang et al. (2007) observed that land cover types significantly affected the distribution of SOC. This conclusion is supported by our results shown in Table 1 and Fig. 5. The results demonstrate that wetlands have the highest SOCD, which is most likely related to a low decomposition rate of soil organic matter and high soil moisture content (Taggart et al., 2012). A notable loss of topsoil SOC as a result of cultivation was observed in China (Song et al., 2005). A significant loss of wetlands to croplands was reported in the Sanjiang Plain in the past few decades (Wang et al., 2009, 2011), which is believed to lead to enhanced carbon emission. These observations imply that the implementation of an effective plan for wetland management, conservation, and restoration in the Sanjiang Plain is required for increasing regional carbon sequestration and reducing the carbon budget. Similarly, effectively reducing the loss of forestlands and properly replacing cultivated land with forestland are essential for balancing the carbon budget (Cao et al., 2011b). Intensive agricultural activities (e.g., tillage) have resulted in enhanced soil mineralization (Lal, 2002), which has led to low SOC in dry farmlands (red and orange colors in Fig. 4). Although a low SOCD was found for croplands, their large areas make them the largest SOC pool among all land-cover types considered in this study (Table 1).

The results show different vertical patterns of SOC storage for the five land-cover types. Grasslands have the shallowest root distribution and less fresh carbon supply in deep soil layers, and they account for a large SOC proportion in the topsoils (Fontaine et al., 2007). The relatively low decomposability and deep root distribution pattern in wetlands can be used to explain the observed difference in the vertical SOC features between wetlands and grasslands (Jobbágy and Jackson, 2000). Loosened soil and plow tillage in dry farmlands, which are favorable to soil respiration, can explain the low SOC storage within the soil depth range of $0-30 \mathrm{~cm}$ in the Sanjiang Plain. In contrast, paddy fields exhibit a high SOC content, which is most likely related to the stability of the soil environment (Pan et al., 2003), suggesting an SOC proportion of the topsoil larger than that in dry farmlands, as shown in Fig. 5. The correlations of SOCD with the examined environmental factors decrease with soil depth. This observation could be related to the changes in vegetation types. Vegetation affects the lateral and vertical patterns of SOC through the distribution and production of above- or belowground biomass. Severe population pressure and misguided policies resulted in significant changes in land-cover types, especially in losses of forestlands and wetlands to croplands (Song et al., 2014; Wang et al., 2012). The SOC storage dynamics controlled by changes of land-cover types needs to be investigated in the future.

\subsection{Relationships between SOC and climate factors}

MAT and MAP explain a large amount of the variation in SOCD in different soil depth ranges (Table 2), implying that climate conditions are an important environmental force in controlling the lateral and vertical distribution of SOC. The results also show that the variance in SOCD is driven less by MAT than by MAP for the soil depth range of $0-30 \mathrm{~cm}$ of the study region. This is consistent with the observation made in France (Martin et al., 2011) because of the humid climate in both France and the Sanjiang Plain.

With respect to the association of SOCD with MAT, SOCD goes down and then up with increasing MAT, which is most likely related to various balances between SOC inputs 
and outputs (Davidson and Janssens, 2006). A decrease in SOCD at low MAT could be caused by low carbon inputs of plant production and high carbon outputs of soil decomposition. MAT is often lower than $4.6^{\circ} \mathrm{C}$ in the Sanjiang Plain. This is why a significantly negative correlation $(r=-0.33$, $P<0.01$ ) is observed between MAT and SOCD (Table 3). By contrast, MAT higher than $4.6^{\circ} \mathrm{C}$ may increase the vegetation productivity and thus contribute to increasing carbon inputs that override the temperature-induced rise in the soil decomposition rate (Yang et al., 2008). Our results confirm the observation made by Yang et al. (2007) that the increasing trend of SOCD from the tropical to cold temperate zone in the eastern part of China is correlated with temperature. In the Sanjiang Plain, MAT can explain $4.23 \%$ of the SOCD variability, suggesting that temperature plays an important role in shaping the pattern of SOC.

In relation to MAP, SOCD values within different soil depth ranges show strong positive correlations to MAP (as shown by the power relationships in Fig. 6b1-b3). These positive correlations can be explained by the fact that precipitation enhances vegetation productivity and thus leads to the accumulation of SOC. This finding is in agreement with the observation made for the spatial pattern of SOC in Northern China, i.e., increasing precipitation contributes to an increase in SOCD from the arid to the semihumid zone (Yang et al., 2007). Similarly, the SOCD of the Sanjiang Plain estimated by this study is higher than that of the Loess Plateau (Liu e al., 2011) due to the difference of the two areas in precipitation. MAP explains the decrease in variation in SOCD when soil depth increases (Table 2) and shows a diminishing correlation with SOCD (Table 3). This can be attributed to relatively low soil moisture in deep soil depth layers, which affects the root vertical distribution with increasing soil depth (Jobbágy and Jackson, 2000).

\subsection{Effects of soil texture on SOC}

The GLM results indicate that the observed soil texture explains 48,44 , and $35 \%$ of the variability of SOCD for the depth ranges $0-30,0-60$, and $0-100 \mathrm{~cm}$, respectively. With regard to all of China, climate was observed as the leading factor driving the spatial pattern of SOCD (Wu et al., 2003; Yang et al., 2007). However, on a smaller regional scale, such as the Sanjiang Plain, the variation in SOCD is mostly attributed to soil texture rather than climate. A similar result was shown in Laos (Chaplot et al., 2010), where SOC storage is mainly controlled by soil types and texture. Soil texture is closely related to the soil water holding capacity and the decomposition rate of organic matter, which thus indicates a key role in shaping the spatial pattern of SOCD on the regional scale (Chaplot et al., 2010). In spite of the fact that climate controls the pattern of SOC storage on a large continental scale, soil texture shows more effects on the distribution of SOC at a small regional level.
This study shows that clay content contributes to the pattern of SOCD more significantly than silt and sand do. This result supports the observation by Jobbágy and Jackson (2000) that clay content is the best predictor of SOCD in deeper depth layers. Moreover, this study shows that SOCD is highly and positively correlated to silt content within different soil depth ranges. This result is expected because high clay and silt contents can stabilize soil organic matter and largely slow down the soil carbon cycle (Hassink et al., 1997). However, negative relationships are observed for SOCD and sand content (Fig. 6e1-e3 and Table 3), which can be explained by the sandy soil properties: low water holding capacity, limited vegetation productivity, and carbon sequestration. Small-magnitude correlation coefficients for sandy soil could be explained by low carbon inputs and relatively efficient decomposition of organic matter within deep soil layers (Ontl et al., 2013).

\subsection{Impacts of agricultural activities on SOC}

Given the fact that both soil texture and vegetation types are highly influenced by climate and that soil texture has obvious effects on vegetation types, these interactive systems drive the SOC distribution in very complicated ways. The GLM results indicate that the examined environmental factors only explain $57.78,52.03$, and $47.67 \%$ of the SOCD variability within the depth range of $0-30,0-60$, and $0-100 \mathrm{~cm}$, respectively. Therefore, we speculate that the anthropogenic factor is critical in explaining the pattern and storage of SOC.

Croplands, including dry farmlands and paddy fields, covering $54.2 \%$ of the whole area of the Sanjiang Plain, have the largest carbon pool among the land types (Table 1). Therefore, the change in SOCD in cropland could result in significant variation in the lateral and vertical distribution of SOC. It is well known that cropland management plays an important role in the carbon exchange of ecosystems (Lal, 2004b). In the Sanjiang Plain, soil tillage and the return of crop stubble into soils have a long history, and they are expected to be a crucial force in shaping the lateral and vertical pattern of SOC (Liu et al., 2006; Mao et al., 2014b). Generally, fertilization can raise SOC storage by enhancing the carbon input from plant productivity and crop biomass (Ren et al., 2012, Zhao et al., 2013). However, overapplication of fertilizer can have negative net effects on carbon sequestration because organic carbon mineralization neutralizes the carbon input (Russell et al., 2005). Influences of fertilization on SOC are complicated and can be related to the history of cropland and vegetation types, as well as soil types and texture. Comparing the amount of fertilizer and SOC on the county scale indicates that the counties using high amounts of fertilizer have low SOC content (Fig. 7). This may reflect different SOC decomposition scenarios due to temperature, soil moisture, and soil types in this plain. Long-term field experiments for different crop types are needed to investigate the effects of fertilization on SOC on the local scale. 


\section{Conclusions}

This study has used kriging, a spatial interpolation technology, and 419 soil sampling sites (1257 profiles in total) collected in 2012 for each of the soil depth ranges of 0-30, 3060 , and $60-100 \mathrm{~cm}$ to determine the SOC storage in the Sanjiang Plain, China. Relationships of SOCD to different environmental factors were examined. The results reveal that the total SOC storage within the depth range of $0-100 \mathrm{~cm}$ in the Sanjiang Plain was estimated to be $2.32 \mathrm{Pg} \mathrm{C}$, and it is mainly stocked in the topsoil. In the Sanjiang Plain, soil texture plays a more important role than climate in determining the distribution of SOC, with clay content contributing more than other observed factors. Vegetation, climate, and soil texture, as well as agricultural activities have remarkable impacts on the storage and distribution of SOC. Wetlands have the highest SOCD as compared to other land-cover types, but they displayed a significant loss in recent decades. Thus, the implementation of an effective wetland management and conservation plan in the Sanjiang Plain is required for fostering regional carbon sequestration. A comparison of the estimate to those by other previous studies demonstrates an underestimation of the SOC storage in the Sanjiang Plain if values from Northeast China and the whole country are used. An accurate and updated estimate of SOC storage from study will significantly improve our knowledge of carbon cycles and the determination of the carbon budget for the Sanjiang Plain.

Acknowledgements. The present paper was jointly supported by the National Natural Science Foundation of China (no. 41371403, 41401502), the CAS/SAFEA International Partnership Program for Creative Research Teams, the National Basic Research Program of China (no. 2009CB421103), and the Professor Fund for IGA, CAS (Y2H1071001). We are very grateful to those who participated in the field soil surveys and to the anonymous reviewers for their comments that resulted in a greatly improved paper.

Edited by: A. Ito

\section{References}

Batjes, N. H.: Total carbon and nitrogen in the soils of the world, Euro. J. Soil Sci., 47, 151-163, 1996.

Batjes, N. H. and Dijkshoorn, J. A.: Carbon and nitrogen stocks in the soils of the Amazon Region, Geoderma, 89, 273-286, 1999.

Cao, S.: Impact of China's large-scale ecological restoration program on the environment and society: achievements, problems, synthesis, and applications, Critical Reviews in Environ. Sci. Technol., 41, 317-335, $2011 \mathrm{~b}$.

Cao, S., Sun, G., Zhang, Z., Chen, L., Feng, Q., Fu, B., McNulty, S., Shankman, D., Tang, J., Wang, Y. and Wei, X.: Greening China Naturally, Ambio, 40, 828-831, 2011a.
Chaplot, V., Bouahom, B., and Valentin, C.: Soil organic carbon stocks in Laos: spatial variations and controlling factors, Glob. Change Biol., 16, 1380-1393, 2010.

Conant, R. T., Ogle, S. M., Paul, E. A., and Paustian, K.: Measuring and monitoring soil organic carbon stocks in agricultural lands for climate mitigation, Front. Ecol. Environ., 9, 169-173, 2011.

Davidson, E. A. and Janssens, I. A.: Temperature sensitivity of soil carbon decomposition and feedbacks to climate change, Nature, 440, 165-173, 2006.

Dorji, T., Odeh, I. O. A., Field, D. J., and Baillie, I. C.: Digital soil mapping of soil organic carbon stocks under different land use and land cover types in montane ecosystems, Eastern Himalayas, Forest Ecol. Manag., 318, 91-102, 2014.

Eswaran, H., Berg, E. V. D., and Reich, P.: Organic carbon in soils of the world, Soil Sci. Soc. Am. J., 57, 192-194, 1993.

Fontaine, S., Barot, S., Barré, P., Bdioui, N., Mary, B., and Rumpel, C.: Stability of organic carbon in deep soil layers controlled by fresh carbon supply, Nature, 450, 227-280, 2007.

Garnett, M. H., Inseson, P., Stevenson, A. C., and Howard D. C.: Terrestrial organic carbon in a British moorland, Glob. Change Biol., 7, 375-388, 2001.

Hassink, J.: The capacity of soils to preserve organic $\mathrm{C}$ and $\mathrm{N}$ by their association with clay and silt particles, Plant Soil, 191, 7787, 1997.

Heikkinen, J., Ketoja, E., Nuutinen, V., and Regina, K.: Declining trend of carbon in Finnish cropland soils in 1974-2009, Glob. Change Biol., 19, 1456-1469, 2013.

Jobbágy, E. G. and Jackson, R. B.: The vertical distribution of soil organic carbon and its relation to climate and vegetation, Ecol. Appl., 10, 423-436, 2000.

Khalil, M. I., Kiely, G., Brien, P. O., and Müller, C.: Organic carbon stocks in agricultural soils in Ireland using combined empirical and GIS approaches, Geoderma, 193, 222-235, 2013.

Kumar, S., Lal, R., and Liu, D.: A geographically weighted regression kriging approach for mapping soil organic carbon stock, Geoderma, 189, 627-634, 2012.

Lal, R.: Soil carbon dynamics in cropland and rangeland, Environ. Pollut., 116, 353-362, 2002.

Lal, R.: Soil carbon sequestration impacts on global climate change and food security, Science, 304, 1623-1627, 2004a.

Lal, R.: Agricultural activities and the global carbon cycle, Nutr. Cycl. Agroecosys., 70, 103-116, 2004b.

Li, Z. and Zhao, G.: Organic carbon content and distribution in soils under different land uses in tropical and subtropical China, Plant Soil, 231, 175-185, 2001.

Liu, D., Wang, Z., Zhang, B., Song, K., Li, X., Li, J., Li, F., and Duan, H.: Spatial distribution of soil organic carbon and analysis of related factors in croplands of the black soil region, Northeast China, Agr. Ecosyst. Environ., 113, 73-81, 2006.

Liu, Z., Shao, M., and Wang, Y.: Effect of environmental factors on regional soil organic carbon stocks across the Loess Plateau region, China, Agr. Ecosyst. Environ., 142, 184-194, 2011.

Mao, D., Wang, Z., Li, L., Song, K., and Jia, M.: Quantitative assessment of human-induced impacts on marshes in Northeast China from 2000 to 2011, Ecol. Eng., 68, 97-104, 2014a.

Mao, D., Wang, Z., Wu, C., Zhang, C., and Ren, C.: Topsoil carbon stock dynamics in the Songnen Plain of Northeast China from 1980-2010, Fresen. Environ. Bull., 23, 531-539, 2014b. 
Martin, M. P., Wattenbach, M., Smith, P., Meersmans, J., Jolivet, C., Boulonne, L., and Arrouays, D.: Spatial distribution of soil organic carbon stocks in France, Biogeosciences, 8, 1053-1065, doi:10.5194/bg-8-1053-2011, 2011.

$\mathrm{Ni}$, J.: Carbon storage in Chinese terrestrial ecosystems: approaching a more accurate estimate, Clim. Change, 119, 905-917, 2013.

Ontl, T. A., Hofmockel, K. S., Cambardella, C. A., Schulte, L. A., and Kolka R. K.: Topographic and soil influences on root productivity of three bioenergy cropping systems, New Phytol., 199, 727-737, 2013.

Pan, G., Li, L., Wu, L., and Zhang, X.: Storage and sequestration potential of topsoil organic carbon in China's paddy soils, Glob. Change Biol., 10, 79-92, 2003.

Piao, S., Fang, J., Ciais, P., Peylin, P., Huang, Y., Sitch, S., and Wang, T.: The carbon balance of terrestrial ecosystems in China, Nature, 458, 1009-1014, 2009.

Ping, C., Michaelson, G. J., Jorgenson, M., Kimble, J. M., Epstein, H., Romanovsky, V. E., and Walker D. A.: High stocks of soil organic carbon in the North American Arctic region, Nature Geosci., 1, 615-619, 2008.

Poeplau, C. and Don, A.: Sensitivity of soil organic carbon stocks and fractions to different land-use changes across Europe, Geoderma, 192, 189-201, 2013.

Post, W. M., Emanuel, W. R., Zinke, P. J., and Stangenberger, A. G.: Soil carbon pools and world life zones, Nature, 298, 156159, 1982.

Ren, W., Tian, H., Tao, B., Huang, Y., and Pan, S.: China's crop productivity and soil carbon storage as influenced by multifactor global change, Glob. Change Biol., 18, 2945-2957, 2012.

Russell, A. E., Laird, D. A., Parkin, T. B., and Mallarino, A. P.: Impact of nitrogen fertilization and cropping system on carbon sequestration in Midwestern Mollisols, Soil Sci. Soc. Am. J., 69, 413-422, 2005.

Saiz, G., Bird, M. I., Domingues, T., Schrodt, F., Schwarz, M., Feldpausch, T. R., Veenendaal, E., Djaabletey, G., Hien, F., Compaore, H., Diallo, A., and Lioyd, J.: Variation in soil carbon stocks and their determinants across a precipitation gradient in West Africa, Glob. Change Biol., 18, 1670-1683, 2012.

Song, G., Li, L., Pan, G., and Zhang, Q.: Topsoil organic carbon storage of China and its loss by cultivation, Biogeochemistry, 74, 47-62, 2005.

Song, K., Wang, Z., Li, L., Tedesco, L., Li, F., Jin, C., and Du, J.: Wetlands shrinkage, fragmentation and their links to agriculture in the Muleng-Xingkai Plain, China, J. Environ. Manage., 111, 120-132, 2012.

Song, K., Wang, Z., Du, J., Liu, L., Zeng, L., and Ren, C.: Wetland degradation: its driving forces and environmental impacts in the Sanjiang Plain, China, Environ. Manage., 54, 255-271, 2014.

Taggart, M., Heitman, J. L., Shi, W., and Vepraskas, M.: Temperature and water content effects on carbon mineralization for sapric soil material, Wetlands, 32, 939-944, 2012.

Wang, S., Zhou, C., Liu, J., Tian, H., Li, K., and Yang, X.: Carbon storage in northeast China as estimated from vegetation and soil inventories, Environ. Pollut., 116, 157-165, 2002.
Wang, S., Huang, M., Shao, X., and Mickler, R. A.: Vertical distribution of soil organic carbon in China, Environ. Manage., 33, 200-209, 2004.

Wang, Y. and Cao, S.: Carbon Sequestration may have negative impacts on ecosystem health, Environ. Sci. Technol., 45, 17591760, 2011.

Wang, Z., Zhang, B., Zhang, S., Li, X., Liu, D., Song, K., Li, J., Li, F., and Duan, H.: Changes of land use and of ecosystem service values in Sanjiang Plain, Northeast China, Environ. Monit. Assess., 112, 69-91, 2006.

Wang, Z., Liu, Z., Song, K., Zhang, B., Zhang, S., Liu, D., Ren, C., and Yang, F.: Land use changes in Northeast China driven by human activities and climatic variation, Chin. Geogra. Sci., 19, 225-230, 2009.

Wang, Z., Song, K., Ma, W., Ren, C., Zhang, B., Liu, D., Chen, J., and Song, C.: Loss and fragmentation of marshes in the Sanjiang Plain, Northeast China, 1954-2005, Wetlands, 31, 945954, 2011.

Wang, Z., Wu, J., Madden, M., and Mao, D.: China's wetlands: conservation plans and policy impacts, Ambio, 41, 782-786, 2012.

Wu, H., Guo, Z., and Peng, C.: Distribution and storage of soil organic carbon in China. Global Biogeochem. Cy., 17, 1048, doi:10.1029/2001GB001844, 2003.

Xie, Z., Zhu, J., Liu, G., and Cadisch, G.: Soil organic carbon stocks in China and changes from 1980s to 2000s, Glob. Change Biol., 13, 1987-2007, 2007.

Yang, Y., Mohammat, A., Feng, J., Zhou, R., and Fang, J.: Storage, patterns and environmental controls of soil organic carbon in China, Biogechemistry, 84, 131-141, 2007.

Yang, Y., Fang, J., Tang, Y., Ji, C., Zheng, C., He, J., and Zhu, B.: Storage, patterns and controls of soil organic carbon in the Tibetan grasslands, Glob. Change Biol., 14, 1592-1599, 2008.

Yang, Y. H., Fang, J. Y., Guo, D. L., Ji, C. J., and Ma, W. H.: Vertical patterns of soil carbon, nitrogen and carbon: nitrogen stoichiometry in Tibetan grasslands, Biogeosciences Discuss., 7, 124, doi:10.5194/bgd-7-1-2010, 2010.

Yu, D., Shi, X., Wang, H., Sun, W., Chen, J., Liu, Q., and Zhao, Y.: Regional patterns of soil organic carbon stocks in China, J. Environ. Manage., 85, 680-689, 2007.

Yu, J., Wang, Y., Li, Y., Dong, H., Zhou, D., Han, G., Wu, H., Wang, G., Mao, P., and Gao, Y.: Soil organic carbon storage changes in coastal wetlands of the modern Yellow River Delta from 20002009, Biogeosciences, 9, 2325-2331, doi:10.5194/bg-9-23252012, 2012.

Zhang, M., Wu, B., Meng, J., Dong, T., and You X.: Fallow land mapping for better crop monitoring in Huang-Huai-Hai Plain using HJ-1 CCD data, IOP Conf.: Earth Environ. Sci., 17, 012048, doi:10.1088/1755-1315/17/1/012048, 2014.

Zhao, G., Bryan, B., King, D., Luo, Z., Wang, E., Song, X., and Yu, Q.: Impact of agricultural management practices on soil organic carbon: simulation of Australian wheat systems, Glob. Change Biol., 19, 1585-1597, 2013. 